\title{
Lithosphere-ionosphere relationship: A new way to predict earthquakes?
}

\begin{abstract}
Analysis of the structure of the ionosphere above seismically active regions has revealed specific disturbances of the ionosphere for several days before strong earthquakes. A new look at the relationship between the lithosphere and the ionosphere has provided an explanation, apparently, of the statistical regularities of the ionospheric disturbances. These disturbances seem to be caused by internal gravity waves as they pass through the ionosphere. The waves are generated in seismically active regions by the Earth's seismogravity oscillations, and the oscillations themselves become a "trigger" that sets off the impending earthquake. Perhaps these oscillations and their resulting ionospheric disturbances will help predict major earthquakes in the future. (Ed.)
\end{abstract}

\section{Introduction}

The ionosphere is the upper part of the envelope of air (the atmosphere) that surrounds the Earth and is ionized by solar radiation. Perturbation of the ionosphere by natural geophysical activity, such as volcanic eruptions and earthquakes, has been studied since the great Alaskan earthquake in 1964 in the United States (Davies and Baker, 1965; Leonard and Barnes, 1965; for a comprehensive review, see Blanc, 1985). The purpose of these studies has been to identify ionospheric disturbances mainly after the event. However, in our opinion, the study of the ionospheric state immediately before an earthquake is of particular interest (Liperovsky and others, 1992) because the ionospheric perturbations caused by an impending earthquake could be regarded as precursors to earthquakes. This opinion is reasonable because physical bonds exist among the lithosphere, atmosphere, and ionosphere.

First, in accordance with experiments, the relationship between the lithosphere and the atmosphere has been recognized at its full scale from below the Earth's surface (the coastal effect of geomagnetic pulsations, disturbances of the atmosphere's electrical potential) to the stratosphere (the formation and disappearance of cloudy structures above geologic heterogeneities, the orographic effect) to the ionosphere (the coastal effect in aurora, radio aurora above deep faults, meteorological effects) (see Danilov and others, 1987; Popov and others, 1989; Liperovsky and others, 1992, and references therein).

Second, the relationship mentioned above is conditioned by the discrete (that is, inhomogeneous) structure of the Earth's crust. As a rule, the boundaries between the anomalies of geophysical fields and the corresponding geologic structures clearly coincide. This fact is especially important and should be kept in mind. It was introduced by M.A. Sadovsky (Sadovsky, 1979) as the concept of "geophysical media" (the solid envelope of the Earth), the principal property of which was supposed to be a discrete, hierarchical structure. It follows that energy redistribution among the media elements takes place during the deformation process that is caused by an external source. The loss of stability of the media elements arises on different hierarchical levels as a result of the type of energy exchange. At this time, the strong earthquake may be regarded as the final stage of the self-organization of lower order structural elements into higher order ones (space-time dissipative structure), which is followed by rupture during the strong earthquake (Sadovsky and Pisarenko, 1991; Bak and Tang, 1989).

For the self-organization effects to exist, the flow of energy into the system from external sources is necessary, as is the following dissipation into the thermostat. One of the Earth's envelopes, the atmosphere, may be considered as a sort of thermostat. In this case, a third assumption to be emphasized is that, if the relationship among geospheres exists without the essential seismicity, the relationship will be more marked during activation of the seismic process.

\section{Observations}

In light of these facts, let us take into account the data of ionospheric observations in seismically active regions immediately before an earthquake.

Studies of ionospheric response prior to the time of an earthquake have involved, for the most part, the $E$ layer $(100-130 \mathrm{~km}$ above the Earth's surface) and the F layer $(200-350 \mathrm{~km})$ of the ionosphere above seismically active regions. These studies have been carried out both by using ground-based techniques and by using low-altitude satellites (for details, see Liperovsky and others, 1992). In order to distinguish the variations that are of a seismic nature, we must assume that the ionospheric response to the process of preparation before a strong earthquake differs from other ionospheric responses (background parameters) that are obtained during seismically quiet times. Essentially, the hypothesis takes into account whichever method among the ones known today is used to forecast an earthquake, and apparently, it may be used in the search for ionospheric precursors to earthquakes.

In order to solve this problem, it is natural to use the long-term series of ionospheric observations that exist for seismically active regions (the Caucasus in southwestern Russia, central Asia, the Kamchatka in northeastern Russia), where hundreds of earthquakes have taken place. Two series of articles have to be picked from among the ones on this subject. In these articles, several ionospheric parameters were analyzed, including research on night-sky airglow $(5,577-\AA$ and $6,300-\AA$ lines) and density variations in the $F$ layer (for example, at the fixed altitude of $300 \mathrm{~km}$ ) and in the $E$ layer (variability of the sporadic E layer) (Toroshelidze and Fishkova, 1988; Fishkova and Toroshelidze, 1989; Liperovsky and others, 1992). 
The statistical results of vertical ionospheric sounding carried out every 15 minutes in seismically active regions make it possible to conclude the following for strong earthquakes (magnitude of about 4.5 or greater) that have taken place close to the sounding station $\left(\mathrm{r}<\mathrm{R}=\mathrm{e}^{\mathrm{M}}\right)$, where $\mathrm{r}$ is the distance from the station, $\mathrm{R}$ is the radius of the region where deformation processes took place before an earthquake of magnitude $M$, and $\mathrm{e}$ is an exponent): (1) A considerable increase in the variability of the sporadic E layer was observed during the 2 days before an earthquake; (2) the density of plasma in the $F$ layer began to increase, on average, several days before a shock, although the tendency exists for a whirlwind-like decline in the density of the layer 1 day prior to an event near the epicenter; and (3) at the same time, quasi-wave variations in density (at an altitude of $300 \mathrm{~km}$ ) of a duration of longer than about 2 hours were two times as many on seismically active nights as on the background nights.

The emission layer of atomic oxygen (OI) $5,577 \AA$ (green line) is situated at an altitude of $85-100 \mathrm{~km}$, which corresponds to the ionospheric $\mathrm{E}$ region, and the emission layer in the line OI $6,300 \AA$ (red line) is situated at an altitude of $200-300 \mathrm{~km}$, which corresponds to the ionospheric $\mathrm{F}$ region. Hence, we may expect that photometric observations and ionospheric vertical sounding data are interconnected.

Analysis of the data accumulated over many years of observations in seismically active regions leads to the following conclusions: (1) Several days before an earthquake, the number of "throw offs" of $5,577-\AA$ intensity increases compared to the background period; (2) at the same time, an anomalous increase (on average) is observed in emission intensity of the green line; and (3) for the red oxygen line, the increasing emission intensity several days before an earthquake is replaced by a decreasing intensity 1 day before the event. Evidently, the growth of the "throw offs" number means an increase in the variability of the $5.577-\AA$ emission layer. This phenomenon is analogous to the previously noted increase in the variability of the sporadic E layer during seismically active periods.

The strong dependence of the intensity of the 5,577- $\AA$ emission layer on the temperature and on the neutral component of the atmosphere determines its high sensitivity to the dynamic processes in the mesosphere and thermosphere and, at the same time, its isolation from the plasma. Hence follows this significant conclusion: the variability of both parameters (the $5,577-\AA$ intensity and the sporadic E layer density) may result from the same condition, which is connected largely with the neutral component of the atmosphere (for a detailed discussion, see Shalimov and others, 1991). In particular, almost in-phase variations exist that are caused by the propagation of internal gravity waves when a sudden increase in $5,577-\AA$ emission intensity coincides with a decrease in the sporadic $E$ layer density.

\section{Interpretation}

Surprisingly, no generally accepted point of view has dominated up to now on the interpretations of observations on the ionosphere above seismically active regions, although we do not lack hypotheses. For example, the variations in airglow have been connected with the existence of hypothetical, very low frequency (VLF) radio emissions during the processes of shifting and cracking that take place along active faults and then intensify before an earthquake. The interaction between the energetic, trapped electrons of the inner magnetosphere and the seismic, VLF emissions may cause the stimulated precipitation of particles and the following variations in glow. In addition, the same observations have been explained theoretically by the vertical movement of ionospheric plasma within a rather strong, quasi-static, seismogenesis electric field. The variations in glow also have been attributed to the dissipation of infrasonic radiation emitted from the epicenter of an earthquake prior to its taking place (Toroshelidze and Fishkova, 1988; Fishkova and Toroshelidze, 1989). Finally, another hypothesis assumes that the large-scale current flowing along a future fault induces corresponding electromagnetic fields in the ionosphere. This hypothesis often has been used for the interpretation of ionospheric effects in the ionospheric $\mathrm{E}$ and $\mathrm{F}$ layers for an earthquake that is about to happen (Liperovsky and others, 1992). Therefore, how will we resolve the question about the nature of the relationship between the lithosphere and the ionosphere? Is it electromagnetic or infrasonic in origin, or is it of another origin?

Some evidence does not confirm the hypothesis of an electromagnetic relationship between the lithosphere and the ionosphere before an earthquake (Shalimov and others, 1991). For example, specific ionospheric irregularities above seismically active regions usually are observed during magnetically quiet times. Hence, they could not be controlled, for example, by joule heating of the ionosphere by means of an auroral electrojet, as this normally takes place during magnetically active periods (Rishbeth and Garriott, 1969). If a local electromagnetic influence were to exist, an increase in local geomagnetic activity, as judged by ionospheric perturbations, would be found in the region of an earthquake, but this is not the case. Besides, the specific ionospheric structure above the seismically active region would last about 1 day after an earthquake (Liperovsky and others, 1992). However, even if ionospheric perturbations before an event could be explained by seismoelectromagnetic phenomena resulting from the processes of the shifting and cracking of the Earth's crust, we would have no reason to suppose that these perturbations would last after the stress is released.

In fact, neither electromagnetic nor infrasonic hypotheses can explain the whole of the experimental data. Therefore, looking at this problem from another aspect is necessary.

According to the seismic model, immediately before an earthquake the crustal blocks in a seismically active region achieve the high-order state, and the density of elastic energy of the geophysical media amounts to a value over which the system becomes unstable (Sadovsky and Pisarenko, 1991). The energy that is needed for the destruction of the metastable state is added to the system by the considerable variations in elastic energy flow coming from external sources.

In studies of sufficiently strong earthquakes, the variations in elastic energy flow may result from so-called seismogravity oscillations (having a super long period of time of approximately 1-3 hours) of the Earth (Lin'kov and others, 1990). These global oscillations always are observed and become more intensive several days before a strong earthquake. At the same time, seismogravity oscillations may be regarded as a source of atmospheric oscillations (in particular, the lines of spheroidal oscillation, ${ }_{0} \mathrm{~S}_{2}$, have been found in the microbarographic spectra).

In general, the lithosphere-ionosphere relationship may be interpreted in the following way (Shalimov, 1992): Seismogravity oscillations increase in amplitude in a seismically active region because of the block structure of the Earth's crust (for example, see Latynina and Shishkina, 1978), and these oscillations affect the atmosphere as a "piston" immediately before an earthquake. In so doing, internal gravity waves (IGW) are generated (these atmospheric waves were investigated first by Hines, 1960). The group velocity of the waves has a vertical component, which may be large enough to reach the ionospheric layers. It is essential, while keeping the energy of the vibration motion, for the amplitude of the vibration velocity of the waves to increase as the waves pass through the gas of decreasing density (atmosphere) (the intensification coefficient is an order of $10^{5}$ ). In addition, the dynamic effect of the IGW in the ionosphere's sporadic $E$ and $F$ layers is H/L times as much as that in the background plasma ( $\mathrm{L}$ being the scale for the vertical gradient of the 
plasma layer and $\mathrm{H}$ being the height scale of homogeneous atmosphere). Naturally, just at the height of the ionospheric layers, the most favorable conditions have to be present in order to observe the atmosphere's perturbations, including the ones caused by the Earth's oscillations. As a result, this description of the response of the ionosphere's sporadic E and F layers to the passing IGW allows all of the observed data to be explained (Shalimov and others, 1991).

\section{Conclusions}

Analysis of the reliable experimental data that have been obtained by research on the ionosphere above seismically active regions has enabled us to infer that specific ionospheric disturbances are conditioned by variations in the neutral component of ionospheric plasma. These disturbances seem to be caused by internal gravity waves as they pass through the ionosphere. The waves are generated in seismically active regions by the Earth's intensive seismogravity oscillations, and the oscillations themselves become a "trigger" that sets off the impending earthquake.

As a further step, it would be useful to verify this concept by studying the ionospheric structure above the San Andreas fault system in the western United States. Perhaps one day we will be able to use the seismogravity oscillations and their resulting ionospheric disturbances to help us predict major earthquakes.

\section{References}

Bak, P., and Tang, C., 1989, Earthquakes as a self-organized critical phenomenon: Journal of Geophysical Research, v. 94, no. B11, p. $15635-15637$.

Blanc, E., 1985. Acoustical disturbances in the ionosphere: A review: Annales Geophysicae, v. 3, no. 6, p. 673-688.

Danilov, A.D., Kazimirovsky, E.S., Vergasova, G.V., and Khachikyan, G.Yu., 1987. Meteorological effects in the ionosphere: Leningrad, Gidrometeoizdat, 271 p. [In Russian.]

Davies, K., and Baker, D.M., 1965, Ionospheric effects observed around the time of Alaskan earthquake of March 28, 1964: Journal of Geophysical Research, v. 70, no. 9, p. 2251-2263.

Fishkova, L.M., and Toroshelidze, T.I., 1989, Reflection of seismic activity in night airglow variations: Aurora and Airglow, no. 33, p. 17-23. [In Russian.]

Hines, C.O., 1960, Internal atmospheric gravity waves at ionospheric heights: Canadian Journal of Physics, v. 38, no. 11, p. 1441-1481.

Latynina, L.A., and Shishkina, T.P., 1978, The intensity of tidal and tectonic movements in the Surkhob fault zone: Physics of the Solid Earth (English edition), v. 14 , no. 6, p. $445-450$.
Leonard, R.S., and Barnes, R.A., 1965, Observations of ionospheric disturbances following the Alaska earthquake: Journal of Geophysical Research, v. 70 , no. 5 , p. $1250-1253$.

Lin'kov, E.M., Petrova, L.N., and Osipov, K.S., 1990, Seismogravity pulsations of the Earth and perturbations of the atmosphere as possible precursors of strong earthquakes: Doklady Akademii Nauk SSSR, v. 313, no. 5, p. 1095-1098. [In Russian.]

Liperovsky, V.A., Pokhotelov, O.A., and Shalimov, S.L., 1992, Ionospheric precursors of earthquakes: Moscow, Nauka Publishers, 270 p. [In Russian.]

Popov, L.N., Krakovetzky, Yu.K., Gokhberg, M.B., and Pilipenko, V.A., 1989. Terrogenic effects in the ionosphere: A review: Physics of the Earth and Planetary Interiors, v. 57, nos. 1-2, p. 115-128.

Rishbeth, H., and Garriott, O.K., 1969, Introduction to ionospheric physics: New York and London, Academic Press, 302 p.

Sadovsky, M.A., 1979, On natural discreteness of the rock: Akademiya Nauk SSSR Doklady, v. 247, no. 4, p. 829-832. [In Russian.]

Sadovsky, M.A., and Pisarenko, V.F., 1991, Seismic process in block media: Moscow, Nauka Publishers, 96 p. [In Russian.]

Shalimov, S.L., 1992, On the influence of the long-period Earth's oscillations on the upper atmosphere: Physics of the Solid Earth, no. 7, p. 89-95. [In Russian.]

Shalimov, S.L., Gladishev, V.A., and Liperovsky, V.A., 1991, Lithosphereionosphere relations before earthquakes: Physics of the Solid Earth, no. 3, p. 26-35. [In Russian.]

Toroshelidze, T.I., and Fishkova, L.M., 1988, Analysis of oscillations of night airglow of middle and upper atmosphere before earthquakes: Doklady Akademii Nauk SSSR, v. 302, no. 2, p. 313-316. [In Russian.]

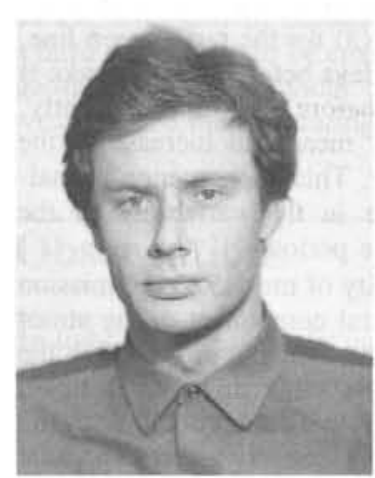

Dr. S.L. Shalimov graduated from the Department of the Earth's Physics and the Department of Theoretical and Applied Spectroscopy, St. Petersburg University, Russia, in 1980 and obtained his doctorate from the Space Research Institute and the Institute of the Earth's Physics in Moscow, Russia, in 1985 by doing theoretical interpretations of plasma processes and physical phenomena in the dayside polar cusps, auroral magnetosphere, and ionosphere. His research interests include solar-terrestrial and lithosphere-ionosphere relationships involving the precursors to earthquakes. His permanent address is 123810 Moscow, B. Gruzinskaya, Institute of the Earth's Physics. 